\title{
Changing practice on confidentiality: a cause for concern
}

\author{
Derek F H Pheby Wessex Regional Health Authority, Winchester
}

\section{Author's abstract}

The dissemination of information about patients through computers and multidisciplinary teams involves departures from traditional tenets of confidentiality. This raises ethical problems, exemplified by current practices in child health. In multidisciplinary teams, problems may arise because different professions utilise different types of data. Some team members may not appreciate the extent to which data may be unscientific and judgmental. Children and their families may be labelled, without justification, preventing objective reappraisal. The ethical and legal implications are considered. Practice may not conform to principles of natural justice, for example when care orders are sought. Obligations to the State may also imperil the confidentiality of the doctor-patient relationship, and of medical records, the legal status of which is confused and requires clarification. Allowing patients access to their records could be a useful safeguard, and the medical profession should devise alternatives should it not be acceptable.

The exchange of information about patients between doctors is as old as medicine itself, and is a necessary part of good clinical practice. It is not generally considered to be an abuse of the confidentiality which has traditionally characterised the doctorpatient relationship because, in the context of the referral process, it is implicit that the patient has given his consent, either overtly or tacitly, to such clinical information as may be considered relevant to his case being imparted to the doctor whose advice is sought. It is thus clear that the transmission of information between professionl colleagues about an individual patient cannot be considered a breach of confidence if it conforms to certain characteristics. The information, for example, must be transmitted only to identifiable individuals, with the patient's full knowledge and consent, and must not be made available to third parties without the patient's agreement. Patients are entitled to the presumption that any referral is made with their interests in mind, and that any information that is transmitted should not prejudice those interests. If the information is accurate and objective, it should "generally fulfil this requirement, but there is a danger, particularly in a pluralistic society, that where value judgments are involved this criterion may not be met.

A current cause for anxiety derives from the growth of the routine collection of data relating to individual patients for statistical purposes. This has arisen because of the rapidly increasing availability, capacity and sophistication of computers, and is associated with a more general disquiet about the use to which personal information in data banks can be put. This unease caused the Government to publish its White Paper on Computers and Privacy ( $I$ ), which led to the establishment of the Lindop Committee on Data Protection. This committee discussed, among other things, the present means by which information on individuals is collated for storage and processing by computer in the NHS (ie the Hospital In-Patient Enquiry, and the Hospital Activity Analysis or HAA), and concluded that there was little risk of breach of confidentiality if such information were used only for bona fide epidemiological or clinical research, and if it were used only in pooled form so that individuals would not be identifiable (2). The committee's report pointed out that it was in fact much harder for an unauthorised person to extract information by illicit means from a computer file than from a manual file. Similar misgivings have been expressed, not least by the British Medical Association (BMA), about the proposed computerisation of child health records (3), though, with proper safeguards, there is no reason why this should not function, as HAA does at the moment, as a useful tool for statistical research, with adequate protection for the confidentiality of individual patients. However, the Lindop committee did not feel that the computerisation of existing child health records could be contemplated with equanimity. It quoted the Health Visitors' Association's evidence to them expressing 'strong concern that the introduction of the National Standard Register presented a threat to privacy, in that information about each child could be placed on computer without its parents' knowledge, and that there was no guarantee that government could not use the information for other purposes' (4). Lindop commented that this concern was justified, since some of the data currently collected by Area Health Authorities (AHAs) about children 'warranted extremely careful safeguards to preserve confidentiality, ranging as they do from "home conditions" to "illegitimate" ... (5).' 
In general, the Lindop report expressed great anxiety about records of all types containing data which it described as 'judgmental'. MIND was quoted as expressing concern about the quality of social work records, and alleging that many such records contained 'information that is inaccurate, subjective and irrelevant ...' (6). Lindop commented that because social work records were widely circulated among a number of agencies, it was 'essential that they should be reliable, fair and accurate and where the data are based on subjective judgments that fact should be clearly indicated' (7). In the field of child health, it is not unusual for doctors to work closely with social workers and other professionals, for example in cases of suspected child abuse. This is largely the result of two phenomena, firstly the increasing professionalism of other occupations, and secondly the great concern which arose during the 1970 , largely as a result of the tragic deaths at their parents' hands of a number of children, including Maria Colwell and Susan Auckland. Indeed, one medical witness at the enquiry into the death of Susan Auckland testified that to circulate information to non-medical professionals concerned with such a case would be no more a breach of professional confidentiality than to discuss the case with another doctor (8). Obviously, no-one would wish to prevent professionals from different disciplines from working together to prevent such tragedies. However, with the extension of the concept of child abuse to include vaguely-defined emotional as well as physical trauma, followed by the further extension that a multidisciplinary approach is an essential part of the health care of children in general, there is a danger that confidentiality may be abused. The Court Report commented 'We have not thought it appropriate to discuss the complex issues involved in the confidentiality of clinical records. We would however wish to state as a matter of principle, that we believe the exchange of information within and between different professions to be essential for the health care of children, and that this should not lightly be foregone on the grounds of confidentiality' (9).

A potential problem can arise from the fact that the different professions engaged in such multidisciplinary exercises often have as their stocks-intrade types of data which are qualitatively different from each other. Doctors are in a difficult position, because the authority which is ascribed to the pronouncements of professionals of different types is generally related to the perceived quality of the data on which those pronouncements are based. Medical opinions are often regarded as authoritative, not only because of the esteem in which the medical profession is held, but also because they are generally considered to be accurate 'scientific' statements derived by an inductive process from objectively ascertainable facts, in comparison with, for example, the rather 'softer' data which behavioural scientists are perceived to use. When doctors venture into the behavioural field, the types of data available to them do not differ greatly in nature from those available to others working in similar fields whose backgrounds may be in the social or behavioural sciences. However, because of the prestige of the medical profession, medical diagnoses in these fields also are often treated as objective conclusions from scientific facts, even though they contain a substantial judgmental element. In addition, when a doctor circulates information originating from another professional, it may acquire a seal of authority from this medical 'fiat', and become at once inaccessible and incapable of correction. For example, there is a danger that teachers' reports may enter medical records in this way (IO). Popper (II) has demonstrated that the major distinguishing characteristic of a scientific hypothesis is that it is falsifiable, and that therefore any hypothesis which is not falsifiable is by definition not scientific. A diagnosis which contains a major element of value judgment cannot be falsified, since value judgments are essentially subjective rather than objective, and there is a danger that where such a value judgment is treated as scientific, any failure to falsify it may be taken to indicate, not that it is unscientific, but that it is essentially true.

The consequence of this failure to distinguish scientific and judgmental data within the multidisciplinary context is that we have allowed to develop a system of consultation in which information is freely circulated among professionals of various types. Much of the data circulated are subjective and judgmental, and can never be falsified. Often, the true nature of the data may be concealed because some of the concepts may be dressed up in scientific-sounding terms, but this can never alter their real natures. For example, in a recent piece of research into an aspect of alleged psychopathology among schoolchildren (12), the author, an educational psychologist (who had full access to his subjects' clinical records), concluded by writing that, if further research were to be undertaken on this subject (ie school phobia), it would be necessary to 'define operationally terms like domineering, overprotective, ineffectual, overindulgent . . . Since a large proportion of the conclusions drawn depended on the use of such terms, it was inappropriate to leave to the end the admission that they had not been defined operationally, and the point should also be made that such terms are value judgments, not objective descriptions, and they are not therefore capable of operational definition.

In child health, the information, frequently unscientific in nature, which circulates between professionals of different disciplines, often does so in a secondhand manner. At case conferences concerned with alleged cases of child abuse, it is by 
no means unusual for only a small minority of those present to have any direct personal knowledge of either the child or its family. The majority are therefore unable to judge for themselves the quality of the evidence on which they are basing their conclusions. Information is tossed back and forth between professionals of different disciplines who form judgments on it and pass it on with their own views appended, so that eventually a remarkably united consensus may be achieved by the multidisciplinary team, the members of which can then quote each other in corroboration of their views. However, underlying the whole edifice may be one single medical pronouncement about some behavioural phenomenon, which, being basically unscientific, can never be falsified. Thus a family or individual can be quite unfairly labelled, and this process is aided and abetted by two further phenomena. The first of these is the tendency, which is well recognised by experts in the psychology of perception, of people to interpret data in the light of their expectations. This can lead to what is called 'fundamental attribution error' (13), when behaviour is attributed to deviance without proper regard to situational factors, be they for example environmental, as in 'total institutions' (I4), or the concurrence of physical disease. Second, there is a tendency for opposed concepts, designed to represent extreme positions, to extend their range of applicability so as to become comprehensive when such a labelling process takes place. For example, the terms 'irresponsible' and 'obsessional' are sometimes used in this context and could be used quite reasonably to denote extremes of human behaviour. However, they must be used with caution since they are to a considerable extent subjective and judgmental, and boundaries therefore cannot be defined. A particular extreme behavioural feature may be merely the end of a spectrum which passes through normality to another extreme, and where either extreme feature disappears cannot be precisely located. Thus in a labelling process, where behaviour is being interpreted in the light of preconceptions in order to fulfil expectations, these terms become comprehensive and mutually exclusive, and a middle ground of 'normality' ceases to exist. The labelled patient who is late for his appointment is 'irresponsible', while the patient who is early or on time is 'obsessional'. The new label then goes to reinforce that already applied. Other examples of similar opposed pairs of terms are hyperactive/lethargic and neglected/repressed. It is characteristic of such terms that, the more widely they are applied, the less meaningful they become. How many parents have been told by health professionals of various types that their child is 'hyperactive', when what is really meant is 'busy'? There are two main types of danger in such a labelling process. The first is that all symptomatology may be interpreted in the light of the label applied, so that physical disease may be overlooked (children labelled as emotionally disturbed are just as likely to have physical diseases as other children). The second danger is that, by diluting the meaning of words such as 'hyperactive', they can no longer be used with much precision in situations where their use might be genuinely appropriate. Stacey (I5) gives three examples where a diagnosis of 'an anxious mum' was made and Librium prescribed. Subsequently the true diagnosis in each case was found to be congenital dislocation of the hip in the child, and Librium for the mother was not an appropriate treatment. It has been argued by the present author (I6) that a labelling process which may take place in the presence of physical disease may be enhanced by acceptance of a lower standard of evidence for emotional disturbance than that generally considered necessary for a diagnosis of physical illness to be made.

It is appreciated that many of those practitioners who have found themselves involved in labelling processes have done so unwittingly, with the best interests of the patient, as they perceived them, as their paramount consideration. There will, of course, be occasions when incorrect labelling results not from inappropriate value judgments but from information being circulated which factually is incorrect. Paradoxically, such information is more scientific in nature than judgmental data, since it is capable of being proved false. In the cases quoted from Stacey above, there were in fact two hypotheses, one non-scientific ('this mother is anxious') and one scientific ('this child is not ill'). The latter 'scientific' hypothesis, being a null hypothesis, could be falsified by a positive finding, and this is clearly what happened eventually, rendering the 'non-scientific' hypothesis irrelevant. Other cases of labelling may be of a similar nature, but where the 'scientific' hypothesis involves historical rather than biological data it may not be a null hypothesis but a positive one. However, such a hypothesis is still intrinsically scientific in nature, because it remains capable of falsification, in this case by demonstration of factual errors in the historical record. The Joint Ethical Working Party of the Royal College of Psychiatrists has pointed out the substantial difference between psychiatric records and other medical records in this respect, in that psychiatric records often contain 'intimate social and longitudinal life histories of patients' (I7), and that therefore great care should be taken to ensure that they are scrupulously accurate and strictly confidential. Where these criteria are not observed, a patient may be labelled as having behaved in a particular deviant way, when the incident quoted may be a matter of erroneous historical record and therefore capable of being disproved. Any doctor who contributed to the labelling of a patient through the dissemination of untrue facts would, if he were in a position to check the veracity of the historical 
record, be abdicating his duty of care not to have done so. If he was unable to check the facts, what he had circulated would have been hearsay, and to have disseminated it without qualification would have been a dereliction of his duty of care. If the facts of the incident were of such a nature as not to be ascertainable in any event, the allegedly factual statement would not be scientific, and should not be treated as such.

Some of the dangers and implications of breaches of medical confidentiality have been outlined above. On several recent occasions, instances of the damage which can be and has been done by failure to observe confidentiality have been published in the medical press. Styles (I8) describes how even criminal records may be included in reports from paediatric clinics to community medical services, and thence widely disseminated, unknown to the patient's family, among various agencies, while the bereaved mother of a baby who suffered a cot death describes the anguish caused to herself and her husband by the local press being notified of the post mortem findings before they were (19). In addition to ethical considerations, there are other aspects of confidentiality which require discussion, including the legal aspects. When a patient consults a doctor, the consultation is privileged, but this privilege is not absolute, as for example, Parliamentary proceedings are, but qualified, or limited. The qualification is that a party to a consultation protected by qualified privilege may at times be constrained to communicate information about the other party which he obtained as a result of the privileged conversation to a third party, such as for example a court, if there are overriding legal reasons why he should do so. If such overriding reasons existed, any doctor who passed on confidential information to a suitably qualified third party such as a court would not run the risk that an action in defamation started by the patient as plaintiff would succeed. However, if the plaintiff were able to demonstrate that there was no such overriding duty on the doctor's part to communicate the information to a third party, either for legal or moral reasons, or to protect the patient's interests, but that the breach of confidentiality had been improper (ie malicious), the defence of qualified privilege would fail and the plaintiff could well succeed in an action in defamation. If, for example, a medical practitioner knowingly and wilfully circulated untrue information to a third party, whether medically qualified or not, if this fact could be demonstrated to a court it is unlikely that a defence of qualified privilege could be sustained.

Further legal considerations arise from the concept of natural justice as it exists in English law. The labelling process is a quasi-legal one, in that it may result in the application of sanctions, which may be tacit, in that a particular treatment may be withheld as a result, or overtly legal, as for example when a care order is obtained, in addition to any stigmatisation that may occur. Because of the informal nature of the labelling process, there are no checks or balances built into it, and, lacking as we do a proper system of administrative law, there are no mechanisms for correcting errors once made. It is simply not true that professional judgments are never incorrect, yet, when errors are brought to light, far from them being corrected, professionals, whose reputations may depend upon how their colleagues perceive the soundness of their judgments, have every incentive to cast around for alternative explanations to justify their initial conclusions. The parents in labelled families may not be listened to, in that their comments may be interpreted subjectively in the light of preconceptions, and they may find themselves subject to care proceedings to which they are not in fact a party and in which therefore they do not have the normal rights of defendants to testify, or to call or examine witnesses. Thus the precept of natural justice audi alteram partem (hear the other side) is not adhered to in either the formal or the informal type of process. The other stipulation for natural justice which exists in English law, nemo iudex in causa sua (no man should be judge in his own cause), may also fail to be upheld in both types of process, since the professionals who are the prime movers in the process may have a strong personal interest in seeing their conclusions upheld. A third principle of natural justice that is often quoted is also frequently denied in the context of care proceedings and antecedent labelling, in that, since parents of children are not generally given access to their children's medical records, they may not know what allegations have been made against them (20). The legal safeguards which do exist in care proceedings are becoming steadily less effective. Thus in 1977, 54 per cent (ie 7600 out of 14100 ) of those children who entered the care of local authorities compulsorily did so without due process of law, in that they were either subject to interim care orders (which may be granted by the police without even the intervention of a magistrate) or were remanded to care. Anyone who thinks that the machinery of child care in the United Kingdom is working well should consider the fact that, with about one hundred thousand children in care (96 200 in 1977), Britain has more children in care in proportion to its population than any other advanced industrialised country. Around fifty thousand children are admitted to care each year, but the proportion subject to care orders has risen from 18 per cent in 1972 (ie 9200 out of 51200 ) to 28 per cent in 1977 (I4 IOO out of 49600 ). For whatever reasons this increase has come about, it must be a matter of grave concern (2I).

In addition to his legal and moral duties, a doctor may have duties to the State arising out of his contractual position, and this is another factor that 
may affect the confidentiality of the doctor-patient relationship. The DHSS expressed the view to the Lindop Committee that the legal right of ownership in NHS medical records was vested in the Secretary of State (22), who might thus on occasion have a legitimate need and a lawful right to see medical records, for example in connection with legal proceedings. The Joint Ethical Working Party of the Royal College of Psychiatrists pointed out that, as a result, any senior official of the DHSS may obtain case notes (23). The right to transfer information in medical records was, in the DHSS,'s view, the Secretary of State's, and the right of anyone in receipt of such information to utilise and circulate it would depend upon the terms of such a transfer. Thus if doctors were to claim that they were acting within their rights in transferring information to third parties, the right on which they based this claim would be delegated by the Secretary of State. The duty of maintaining medical confidentiality (ie of preventing abuses of this right) rested, the DHSS claimed, with those responsible for maintaining the ethics of the medical profession, in other words with the GMC. If the DHSS's opinions were correct, then the GMC's duty of maintaining standards of confidentiality would appear in effect to be a responsibility delegated from the Secretary of State, at least as far as NHS patients are concerned. However, the Home Office Legal Adviser, also in evidence to the Lindop Committee (24), pointed out that information was not susceptible of ownership, whatever the ownership status of the chattel wherein it was originally contained, so it is difficult to see by what right the Secretary of State could legally restrict the uses to which information could be put by transferees of information from medical files. The only safeguard for the patient would then be the law of defamation, assuming that he was in a position to prove that damaging information had been circulated, and subject to a defence of qualified privilege not being sustained, but actions in defamation are not legally aidable. The law of copyright applies only to the actual form of words and not to the knowledge conveyed, and, in any case, serves to protect the author, not the subject, of a document. The position is further confused by a recent circular from the DHSS (25), in which it claimed that what it now termed the 'presumption' that medical records were the property of the Secretary of State had never been tested in the English courts. However, Dr Vaughan the Minister of State for Health, replying (6 May 1980) to a Parliamentary question, said that he 'would not wish the technicality of legal ownership of medical records by the Secretary of State, or custody of medical records by health authorities, to be used to circumscribe the ethical responsibility of doctors for confidentiality in relation to their patients' (26). It has therefore not been clearly established to whom medical records belong, nor what rights of transfer reside in the holders of those records, nor what safeguards if any exist to protect the subjects of these same records against further use by third parties of any information obtained therefrom. What is clear is that the law of defamation is much less of a safeguard for the individual than the maintenance of medical confidentiality. For $\frac{}{0}$ example, an action in defamation may be defended $\frac{\bar{m}}{\omega}$ successfully on the grounds that the information $\overparen{D}$ circulated was true, even if it were conceded to be damaging, but the circulation of damaging infor- ${ }^{-}$ mation should be considered ipso facto a breach of $\vec{\circ}$ medical ethics. It should be noted that merely to be $\overrightarrow{\vec{H}}$ medically qualified does not give the recipient of ${ }^{\omega}$ information greater rights than other possible recipients of the same information in respect of that information. Thus the motion debated at the BMA's I980 Annual Representative Meeting calling for an end to the hospital specialist's right of $N$ transfer of confidential medical information to third parties was effectively wrecked by an amendment $\vec{\overrightarrow{ }}$ excluding the transfer of information to medical practitioners from its provisions (27). However, the $\frac{\widehat{\partial}}{\partial}$ fact that the BMA is nevertheless committed to the maintenance of high standards of confidentiality is underlined by the passage without opposition of ? another resolution at the same meeting 'that the confidentiality of medical records should be sacrosanct' (28).

As a result of these developments, together with the growth of public unease about the possibilities of misuse of confidential records of many types, demands have recently been articulated that patients should have access to their own medical records. These have come not only from groups such 7 as Community Health Councils (29), but also from

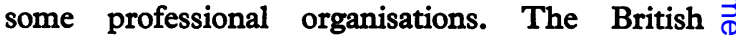
Psychological Society, for example in its evidence to the Lindop Committee (30), expressed the opinion that the patient should have access to both medical and psychological records, and was in addition quoted as saying that 'it was aware that psychological data were often unreliable and potentially harmful to the subject'. Lindop commented that it seemed to be generally accepted by the medical profession that patients should be entitled to know purely factual data on their records (eg blood group, and medical history), but that it was also felt by doctors that items such as diagnosis and prognosis should remain secret at the doctor's discretion, because of the harm such data might do, and because of their frequently speculative and uncertain natures (3I). The Lindop Committee accepted this position, but felt that the climate of opinion was moving towards greater openness. It is clearly very important for many doctors to be able to decide these matters in the best interests of their patients, and the position could be allowed to remain as it is at present, if medical records consisted only of factual data and of speculative opinions such as possible diagnoses and 
prognoses, the uncertain nature of which was well-recognised by professionals concerned with patient care. The author has argued, however, that the present secrecy, in the absence of other checks or balances, may have encouraged an irresponsible attitude to develop on the part of some practitioners, and that it is up to the medical profession, if it wishes to maintain the present position with regard to medical records, to devise suitable safeguards for the interests of patients (32). There is a growing tendency as has been pointed out, for medical records, particularly in certain fields, to include data which are neither factual nor overtly speculative but which masquerade as fact though incorporating a large measure of value judgment. It must be recognised that, in multidisciplinary teams, the backgrounds and knowledge of non-medical personnel may be such as to prevent them interpreting the data correctly, while doctors too may be forced to wrong conclusions at times by a failure to recognise the substantial element of subjectivity in reports which they may receive, for example from teachers or social workers. Doctors are fully entitled to feel that it would be premature at the present time to allow patients access to their medical records, and, in an effort to provide alternative safeguards for patients, an initial course of action might be for doctors to endeavour to limit the extent to which their comments are subjective and judgmental. A diagnosis which may be speculative is admissable insofar as it is falsifiable in the light of new evidence, and facts quoted should be of such a form as to be verifiable. A value judgment is rarely admissible unless its nature is made perfectly clear, because, far from being falsifiable, new evidence will tend often to reinforce it, since the interpretation of such evidence may well be made by a doctor or other professional whose mode of perception has already been altered by the initial value judgment. In any case, since the privilege accorded to medical records is qualified, it is possible that at some stage such records may have to be disclosed, for example in connection with legal proceedings. Any doctor would therefore be prudent to avoid making value judgments as far as possible when writing notes, since what is written may not always remain hidden from view.

In addition to exercising greater care in the compilation of records there is a need for a vigorous reappraisal of the extent to which information about patients needs to be circulated. Doctors who argue that the interests of their patients require this should be able to justify their positions convincingly. It should be recognised that those who depart from traditionally accepted tenets of confidentiality, as the Court Report suggested may at times be justified, are not in the main stream of medical thought throughout the ages. There is little change of emphasis, for example, between the Hippocratic Oath, which states 'Whatsoever things I see or hear ... I will keep silence thereon, counting such things as sacred secrets', and the Geneva Convention Code of Medical Ethics (1949), which puts it rather more succinctly: 'I will respect the secrets which are confided in me' (33). It would of course be untrue to maintain that all doctors have consistently followed this precept since ancient times, but where is has been abandoned in different countries at different times, the inevitable consequence has been a decline in the liberty of the individual. There are parts of the world today where, while confidentiality generally may be respected, the duty of the doctor to the State may override his duty to his patient at times.

At the present time, it is unlikely that the current position will remain unchanged. The Government's definitive response to the Lindop Report is still awaited. Meanwhile, the Law Commission has apparently already called for changes in the law to make breach of medical confidentiality a criminal offence (34), though its final recommendations are also awaited. Within the profession, there is at present an interdisciplinary working party meeting under the aegis of the Royal College of Psychiatrists, whose report is expected soon. Overall, there is a clear public concern about questions of confidentiality, and there could develop a consensus for clarification if not for change. Unless the medical profession is prepared to seize this particular nettle and deal with some of the problems outlined above, it could well find changes which may be unacceptable imposed on it from outside.

\section{References}

(I) White Paper on Computers and Privacy. Cmnd 6353. London: HMSO, 1975.

(2) Report of the Committee on Data Protection (Lindop Report). Cmnd. 734I. London: HMSO, 1978.

(3) BMA criticises Government computer plans. British Medical fournal I980 May 10; 280: 1 I94.

(4) See reference (2) para 7.05 .

(5) See reference (2) para 7.06.

(6) See reference (2) para 9.2I.

(7) See reference (2) para 24.08.

(8) DHSS Report of the Committee of Inquiry into the Provision and Coordination of Services to the family of fohn George Auckland. Auckland Enquiry. London: HMSO, 1978; Day 5: 390-392. In: Carver V, ed. Child Abuse - a study text. Milton Keynes: Open University, 1978: 197.

(9) Fit for the Future - The Report of the Committee on Child Health Services (The Court Report). Cmnd 6684. London: HMSO, 1976: para 21.43.

(I0) Pheby D F H. Recurrent abdominal pain in childhood (letter). British Medical fournal I980; 280: 1377.

(II) Popper K. The logic of scientific discovery. London: Hutchinson, 1959; 40.

(12) Blagg N. PhD Thesis. The Behavioural Treatment of School Refusal. University of London, 1979. 
(13) Hilgard E R, Atkinson R L, Atkinson R C. Introduction to Psychology. New York: Harcourt Brace Jovanovitch, 1979; 7th edn: 542 .

(14) Goffman E. Asylums. Harmondsworth: Penguin, 1978.

(15) Stacey M. Realities for change in child health care: existing patterns and future possibilities.

(16) Pheby D F H. See reference (I0).

(17) Report of the Joint Ethical Working Party of the Royal College of Psychiatrists. British Fournal of Psychiatry I977 Jan: 3.

(I8) Styles W. Confidentiality of medical records for children and their families (letter). British Medical fournal 1980; 28I: 1357.

(I9) Harman W V. Death of my baby. British Medical fournal 1981; 282: 35-37.

(20) Rendel M. Natural justice and disciplinary cases in Britain and France. Public Administration 1981; 58 : 67-86.

(2I) Health and Personal Social Services Statistics 1978. London: HMSO, I980: Tables 7.12-7.16.

(22) See reference (2) para 18.07.

(23) See reference (17).

(24) See reference (2).

(25) Disclosure of medical information. British Medical fournal 1980; 28I : 1299.

(26) Medical confidentiality (Parliamentary questions). British Medical fournal 1980; $28 \mathrm{I}$ : 336.

(27) ARM debates in brief. British Medical fournal 1980; 281: 334 .

(28) Confidentiality. British Medical fournal 1980; 28I: 333.

(29) The Case for: Central Birmingham Community Health Council, 16r Corporation Street, Birmingham, 1980.

(30) See reference (2) para 7.34.

(3I) See reference (2) para 24.05.

(32) Pheby D F H. Confidentiality must not be used as protection for doctors. British Medical Association Nervs Review 1980; 6/10: 64-66.

(33) Campbell A V. Moral dilemmas in medicine. Edinburgh and London: Churchill Livingstone, 1972: 194-195.

(34) Hodges C. Bill will penalise breach of confidence. Pulse 1980 Jan 19: $\mathrm{r}$.

Commentary I : Confidentiality: the dangers of anything weaker than the medical ethic

\section{J M Jacob London School of Economics and Political Science}

Much of the discussion which appears in this journal and elsewhere arises because of developments in modern technology. The discussion of medical records by Mr Kenny and Dr Pheby comes from developments in modern bureaucracy. They imply it is as wasteful to attempt to hold back the developments of the latter as it is those of the former. With bureaucracy, as with technology, the changes in society force not only more precise definitions of principles and rules of law and ethics but also a refinement of them. If we fail to understand the issues, we merely fudge, but do not avoid the refinement. If we differ as to our perception of the issues then it is likely that we will differ as to our definitions.

It is not surprising that these authors provide a challenge to what may be called 'the normal medical view'. The one is an administrator and the other a community physician. As the practice of medicine has grown in complexity so also have the demands of its administration increased. There is little point in members of the two oldest professions (law and medicine) dismissing 'health administration' as not a true 'profession'. The hospital remains a place where the physician can practise his craft but it is no longer a place where he can do so without the skills of those who link the galaxy of personnel of the healing professions, $i e$ its administration.

Community medicine has, of course, always been the poor relation of the surgeon and physician. Over the last I50 years its triumphs have rarely been dramatic but any view of the history of medicine must be prepared to concede its major contribution to the achievement of medicine's goals ( $\mathrm{I}$ ).

It appears that both these authors may have relied too heavily on the existence of interdisciplinary practice. No doubt, as with any of us, their perspective has influenced their perception. Put briefly they are saying that since much of modern medicine is based on such a therapeutic team, older understandings of the basis of medical confidences may have to be modified. Certainly, Kenny is right to point out that the doctor does not have contractual or functional control of many members of the team. However, it is questionable as to whether or not this affects the patient's perception. Surely he still looks to the doctor rather than the institution for his clinical care. Also Pheby is right to make the distinction between hard and soft data in the casenotes and certainly he is right to object that because an entry appears under the hand of a doctor it is not thereby an objective truth. Both physicians and others in the health care teams are capable of making value-laden assessments and of overlooking or forgetting this fact. He is also right to point out the lack of legal remedies for mistakes arising from this fault.

Before proceeding to an examination of either law or ethics, it is important to clarify what medical oo records are and for what they are used. Broadly, the record will contain information from four sources:

I) Information given orally by the patient,

2) Maybe, information given by others,

3) Information generated by the doctor from his own observation (which will include the diagnosis and prognosis), and,

4) Information acquired as a result of X-rays, pathology tests etc which may itself come from either the doctor's own work or from others. 